\title{
GALERI SENI RUPA KONTEMPORER
}

\author{
BRM Suryo Cahyo Sulistyohadi ${ }^{11}$, Lina Purnama ${ }^{2)}$ \\ 1) Program Studi S1 Arsitektur, Fakultas Teknik, Universitas Tarumanagara, suryo_cs@yahoo.com \\ 2) Program Studi S1 Arsitektur, Fakultas Teknik, Universitas Tarumanagara, Ipurnama.112@gmail.com
}

\begin{abstract}
Abstrak
Peran seni merupakan segala sesuatu yang diciptakan manusia yang mengandung unsur keindahan sehingga mampu membangkitkan perasaan orang lain. Namun kurangnya wadah seni yang interaktif berdasarkan teknologi modern, dengan menggunakan konsep edutainment dan yang dapat menampung sebuah pameran seni kontemporer dalam skala besar masih dapat terbilang sedikit banyak ruang serbaguna yang di gunakan sebagai tempat pameran seni. Oleh karena itu penulis melakukan pendekatan Architourism pada isu perancangan dengan menggunakan dasar standar galeri dan mempunyai studio interaktif yang berfungsi sebagai sarana memperkenalkan budaya dan seni kontemporer dengan cara yang lebih modern yang dapat melibatkan pengunjung untuk lebih interaktif dengan media teknologi yang sedang berkembang dan memberikan pengalaman yang berbeda. Perancangan Galeri Seni Rupa Kontemporer di Cikini, Jakarta Pusat ini mempunyai konsep memberikan pengalaman baru untuk menikmati sebuah karya seni dengan media yang berbeda-beda dan memberikan ruang publik yang dapat di pergunakan untuk berinteraksi dan bersantai.
\end{abstract}

Kata kunci: Galeri, Seni, Kontemporer

\begin{abstract}
The role of art is everything that is created by humans that contains elements of beauty and can arouse the feelings of others. But the lack of an interactive art space based on modern technology, using the edutainment concept which can accommodate a large-scale exhibition of contemporary art can still be counted in a number of multipurpose spaces that are used as art exhibition venues. Therefore, the authors approach Architourism on design issues using basic gallery standards and have interactive studios that serve as a means of introducing culture and art in a more contemporary modern way that can engage visitors to be more interactive with developing media technologies and provide different experiences. The design of the Contemporary Art Gallery in Cikini, Central Jakarta has the concept of providing a new experience to enjoy a work of art with different media and provide public space that can be used to interact and relax.
\end{abstract}

Keywords: Gallery, Art, Contemporer

\section{PENDAHULUAN}

\section{Latar Belakang}

Seni kontemporer merupakan kesenian yang berkembang di kota-kota besar seperti DKI Jakarta, D.I.Y Yogyakarta, Bandung, dan lain-lain. Namun wadah yang dapat menampung sebuah pameran seni kontemporer dalam skala besar masih dapat terbilang sedikit banyak ruang serbaguna ( $h a l l$ ) yang di gunakan sebagai tempat pameran seni.

Galeri seni kontemporer merupakan ruang edutainment yang berbasis seni modern yang menggunakan berbagai macam media untuk penyampaian seni yang menyuguhkan informasi dikemas secara menarik dan interaktif. Tidak hanya digunakan sebagai tempat untuk memamerkan, mengapresiasi dan merawat karya seni kontemporer saja, akan tetapi juga digunakan sebagai tempat untuk memberi kajian seni pada masyarakat agar karya seni 
kontemporer bisa di apresiasi dengan benar dan tidak terjadi salah tafsir mengenai apa yang hendak dikomunikasikan seniman melalui karya seni tersebut.

Pada perkembangannya, Cikini dimanfaatkan menjadi kawasan wisata seni dengan potensi yang ada, seperti Taman Ismail Marzuki yang didalamnya mempunyai Institut Kesenian Jakarta (IKJ), namun tidak memiliki ruang pameran yang memadai dan berskala besar. Oleh karena itu, wisata seni yang dikembangkan merupakan dengan pendekatan desain seni kontemporer yang dapat memberikan edukasi pada pengunjung dengan menggunakan teknologi, dengan tata ruang dan seni rupa publik seperti seni lukis, instalasi seni, dan mural. Selain itu, pengunjung dapat berkontribusi dalam program-program workshop pada galeri seni kontemporer ini.

Setelah melihat masalah diatas, dibutuhkan Wadah Galeri Seni Kontemporer, dimana tempat ini dapat mewadahi kreatifitas seniman dengan dipadukan oleh konsep seni modern. Pengedukasian pada galeri seni kontemporer dilakukan dengan konsep yang interaktif menggunakan metode edutainment. Dengan tujuan, pengunjung tidak hanya menikmati seni namun dapat berkontribusi pada seni tersebut melalui workshop dengan program yang ada.

\section{Identifikasi Masalah}

Berdasarkan latar belakang diatas, dapat diidentifikasi beberapa masalah yang akan dijadikan bahan penelitian selanjutnya, yaitu kurangnya wadah seni yang interaktif berdasarkan teknologi modern, dengan menggunakan konsep edutainment, kurangnya minat masyarakat terhadap pameran seni, kurangnya wadah edukasi seni tentang seni kontemporer.

\section{Ruang Lingkup Pembahasan}

Adapun batasan masalah yang dipilih berkaitan dengan perancangan Wadah Galeri Seni Kontemporer yang dibatasi oleh seni lukis, seni instalasi, dan seni mural di wilayah Cikini, Jakarta Pusat. Dimana tempat ini menjadi wadah kegiatan pameran seni interaktif dan edukasi berbentuk workshop.

\section{Perumusan Masalah}

Berdasarkan dari latar belakang tersebut diperoleh rumusan masalah yaitu bagaimana cara mengembangkan perancangan galeri seni kontemporer yang interaktif di Jakarta berdasarkan teknologi modern yang berkembang? Bagaimana menciptakan wadah galeri seni kontemporer yang akan meningkatkan pariwisata seni dan minat masyarakat di Jakarta?

\section{Sasaran Proyek}

Sasaran utama dari proyek ini terbuka untuk umum dan juga dapat dijadikan pembelajaran mengenai seni kontemporer yang meliputi seni lukis, instalasi, seni interaktif selain tu melalui tempat ini pengunjung juga dapat mengalami pengalaman menikmati sebuah seni dengan media yang lebih modern contohnya teknologi.

\section{METODE}

Dalam penelitian ini, metode yang digunakan pada proses perancangan Galeri Seni Kontemporer di Cikini, Jakarta Pusat menggunakan metode deskriptif untuk mengkaji kondisi eksisting, antara lain:

\section{Metode Pengumpulan Data}

Pengumpulan data dilakukan dengan observasi langsung ke lapangan untuk mendapatkan data-data tentang kondisi fisik dengan segala potensi kawasan yang ada, serta aktivitasnya. Pengumpulan data sekunder, diperoleh dari hasil studi literatur yang bertujuan untuk memperdalam analisa yang ada. 


\section{Metode Pengolahan Data}

Data yang terkumpul diolah dan di strukturkan kemudian di analisis dan di interpretasi untuk mendapatkan pemahaman mendalam terhadap Galeri Seni Kontemporer, masalah dan potensi yang dapat di analisis sebagai titik tolak proses perancangan Galeri Seni Kontemporer. Kajian dan studi preseden digunakan untuk pendekatan pada konsep perancangan. Kemudian dilakukan analisis dan sintesis yang meliputi analisis tapak serta beserta potensi lingkungan kawasan serta analisis ruang untuk proses penyusun program ruang, serta bentuk arsitektural. Proses sintesis yang merupakan kesimpulan dari analisis yang dijadikan acuan dan menghasilkan konsep perancangan.

\section{Metode Perancangan}

Menggunakan dua metode yaitu metode tipologi dan pragmatik. Metode tipologi bangunan galeri seni diterapkan pada perancangan dan metode pragmatik digunakan untuk design scheme.

\section{DISKUSI DAN HASIL}

Pemahaman tentang Architourism tidak dapat dipisahkan dari anggapan bahwa arsitektur wisata merupakan pendekatan dimana arsitektur berperan untuk mendukung keperluan pariwisata, yang menjadi penekanan dalam pendekatan ini adalah program wisata yang di wadahi oleh bangunan. Selain berperan untuk mendukung aktivitas, arsitektur sendiri dapat menjadi atraksi wisata atas signifikansi bentuknya terhadap lingkungan, yang kedua di sebut wisata arsitektur yang tidak terbatas pada gaya atau aliran dari periode waktu yang spesifik. Tampilan bentuk ikonik menjadi kunci dalam definisi ini (Specht, 2014).

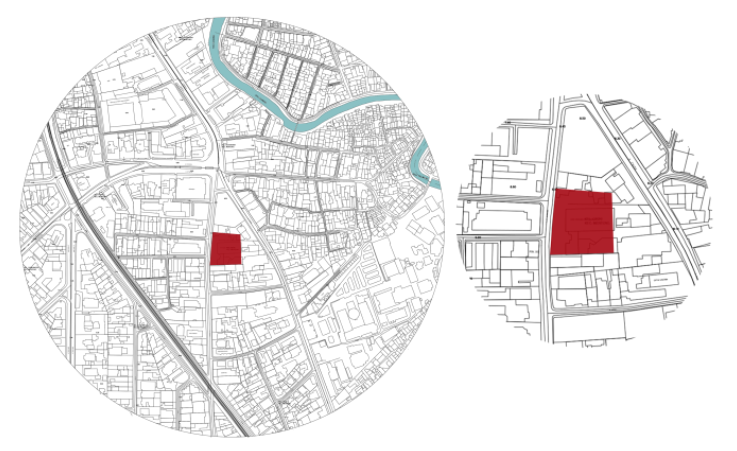

Gambar 1. Peta LRK Autocad Tapak Sumber: dokumen pribadi, 2019

Tapak berada pada Jl. RP Suroso, Cikini, Menteng, Jakarta Pusat, mempunyai luas tapak 4.900 m2. dengan batas wilayah sebagai berikut:

- Utara : Restaurant

- Timur : Gedung perkantoran

- Selatan : Gedung Baptis Indonesia

- Barat : Jl. RP. Suroso

Letak tapak menurut peta lembar rancang kota zonasi DKI Jakarta dikategorikan sebagai zona komersil dengan mayoritas komersil dan zona campuran.

Tabel 1. Tabel Intensitas Ruang

\begin{tabular}{|c|c|c|c|c|}
\hline KDB & KLB & KB & KTB & KDH \\
\hline 55 & 2,00 & 8 & 30 & 55 \\
\hline \multicolumn{5}{c}{ Sumber: LRK Jakarta, 2019} \\
\hline
\end{tabular}

Kunjungan Pariwisata mancanegara di DKI Jakarta mengalami penurunan pada oktober 2017 
dan mengalami kenaikan kunjugan wisatawan mancanegara pada November. [2]

Tabel 2. Statistik Informasi Pariwisata DKI Jakarta

\begin{tabular}{l|r|r|r|}
\hline \multirow{2}{*}{ Is_Pariwisata } & \multicolumn{3}{|c|}{ Is_Pariwisata } \\
\cline { 2 - 5 } & \multicolumn{1}{|c|}{2016} & \multicolumn{2}{|c|}{2017} \\
\cline { 2 - 4 } & November & \multicolumn{1}{|c|}{ Oktober } & November \\
\hline $\begin{array}{l}\text { Kunjungan Wisatawan } \\
\text { Mancanegara }\end{array}$ & 225298 & 221062 & 224079 \\
$\begin{array}{l}\text { Tingkat Penghunian Kamar Hotel } \\
\text { Berbintang }\end{array}$ & 62.59 & 65.22 & 67.30 \\
\hline \multicolumn{4}{|c|}{ Sumber: www.jakarta.bps.go.id } \\
\hline
\end{tabular}

Pada perkembangannya saat ini galeri seni kontemporer tidak hanya digunakan sebagai tempat untuk memamerkan, mengapresiasi dan merawat karya seni kontemporer saja, akan tetapi juga digunakan sebagai tempat untuk memberi kajian seni pada masyarakat agar karya seni kontemporer bisa di apresiasi dengan benar dan tidak terjadi salah tafsir mengenai apa yang hendak dikomunikasikan seniman melalui karya seni tersebut.

\section{Hasil Perancangan}

Konsep perancangan terdiri dari dua massa area yang memiliki area transisi pada bagian tengah bangunan yang menjembatani antara fungsi exhibition dengan fungsi publik. Pada sisi tampak, diberikan double skin pada area muka bangunan yang terkena langsung sinar matahari sore.

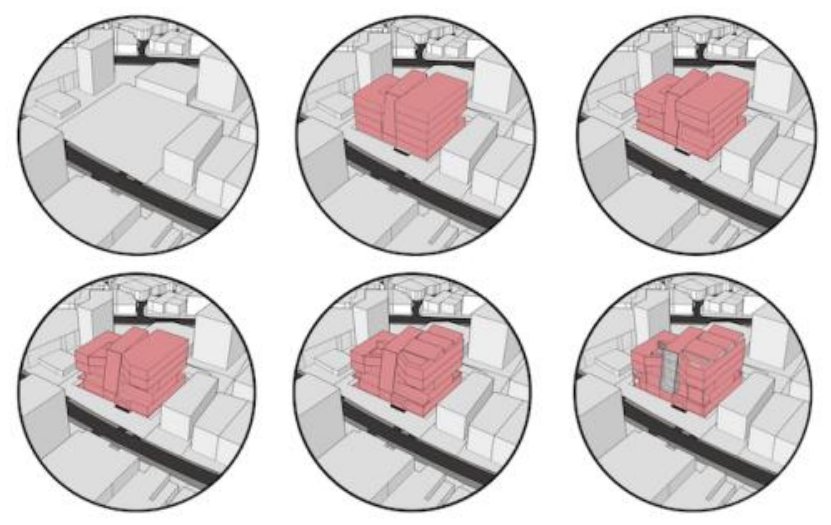

Gambar 2. Design Scheme

Sumber: Dokumen Pribadi, 2019

Design scheme berawal dari gubahan massa yang terbagi atas area publik dan komersil, lalu diolah sedemikian rupa dengan proses yang memaksimalkan bukaan-bukaan yang mempermudah cahaya matahari untuk masuk ke dalam area tengah bangunan, dengan bentuk awal persegi panjang dan kemudian diolah sehingga dapat berbentuk dinamis

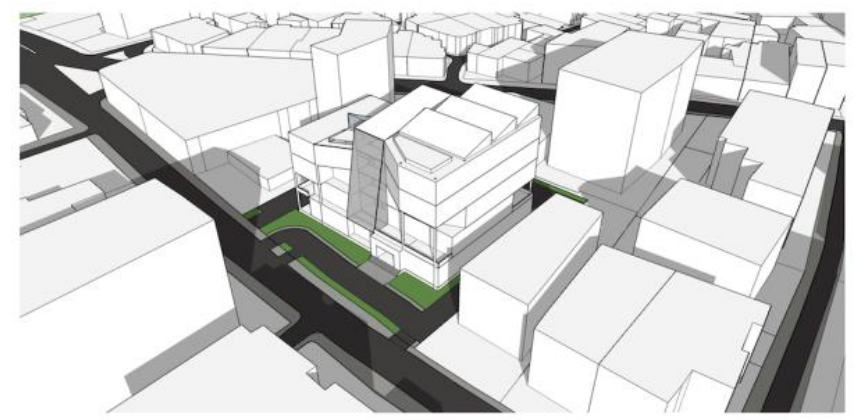

Gambar 3. Gubahan Massa

Sumber: Dokumen Pribadi, 2019 


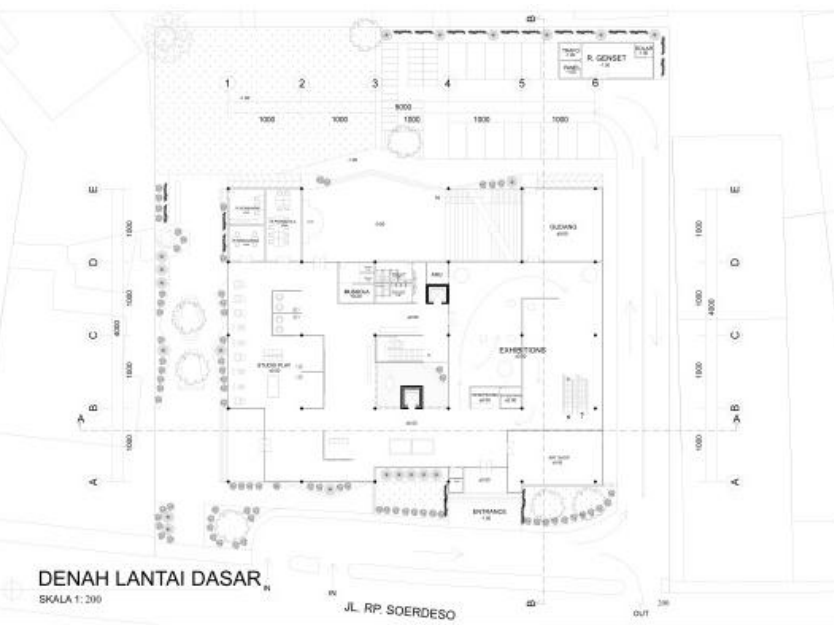

Gambar 4. Denah Lantai Dasar

Sumber: Dokumen Pribadi, 2019

DENAH LANTAI 2

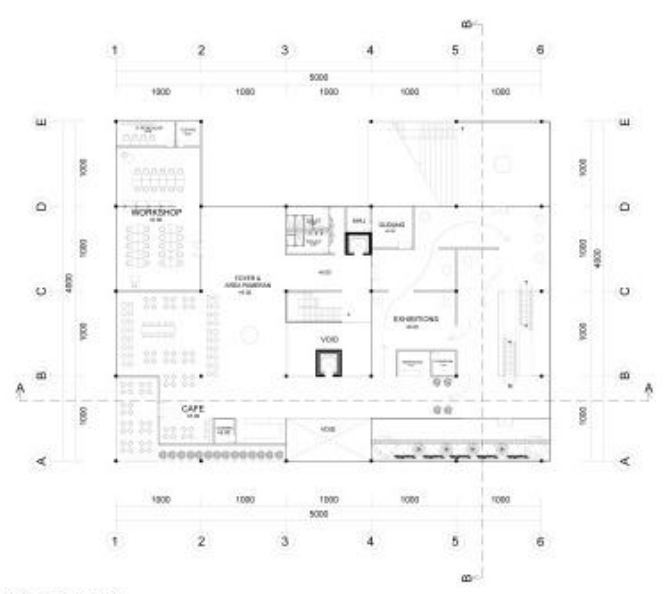

Gambar 5. Denah Lantai 2

Sumber: Dokumen Pribadi, 2019

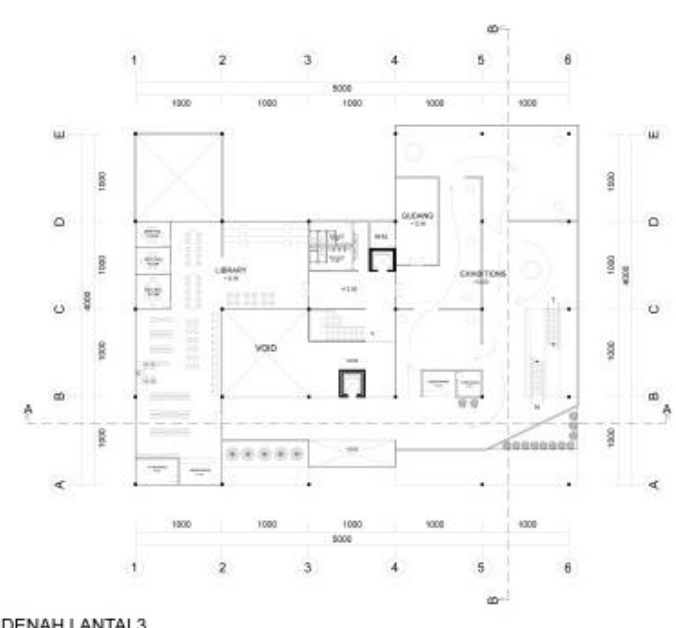

DENAH LANTAI 3
SKGLA 1200

Gambar 6. Denah Lantai 3

Sumber: Dokumen Pribadi, 2019 


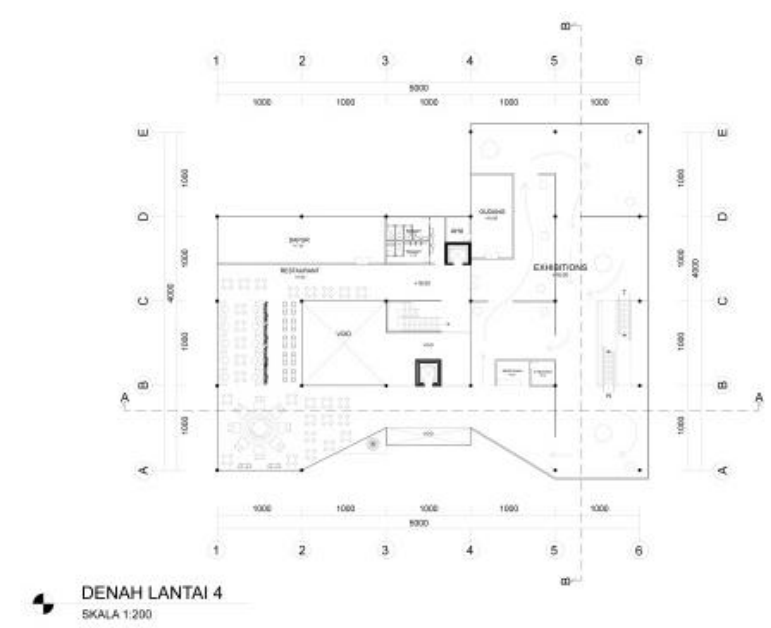

Gambar 7. Denah Lantai 4 Sumber: Dokumen Pribadi, 2019

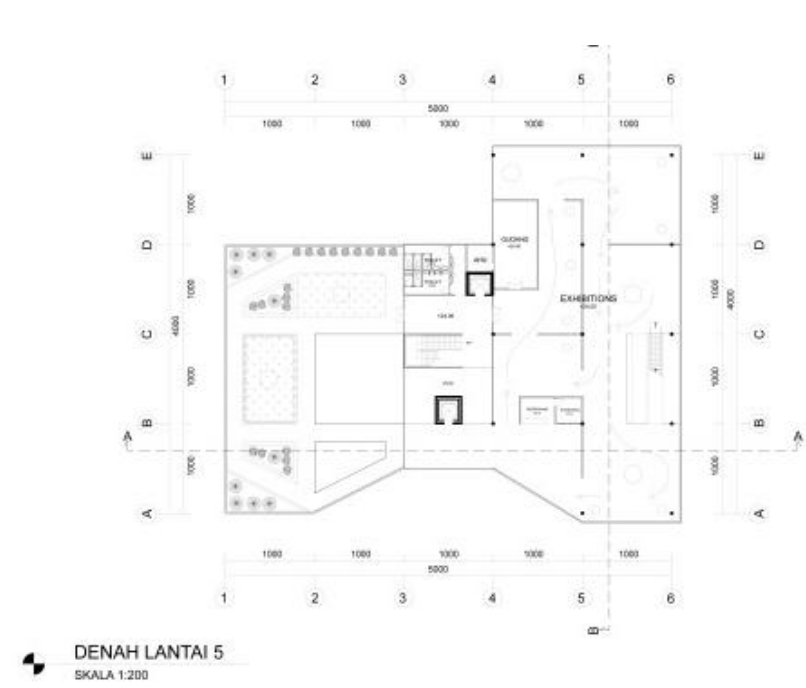

Gambar 8. Denah Lantai 5

Sumber: Dokumen Pribadi, 2019

Massa bangunan di olah sedemikian rupa supaya dapat menerima cahaya alami yang dapat mudah masuk kedalam bangunan dengan memberikan bukaan berupa skylight yang membuat cahaya matahari dapat masuk dari atas menuju area dalam bangunan.

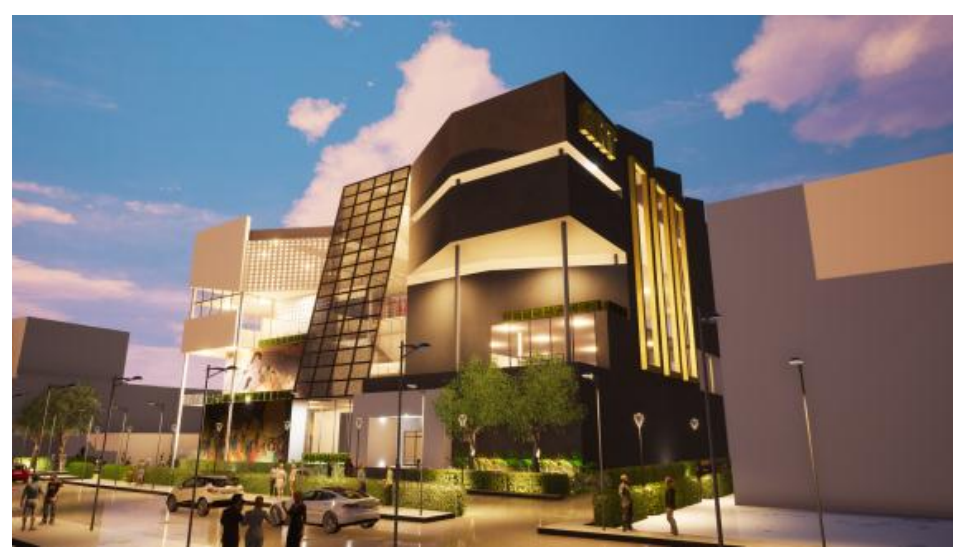

Gambar 9. 3D Exterior

Sumber: Dokumen Pribadi, 2019 


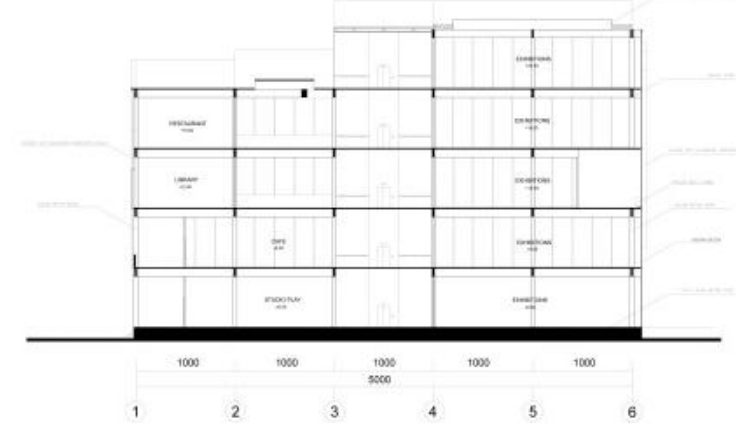

4. POTONGANA-A

Gambar 10. Potongan

Sumber: Dokumen Pribadi, 2019

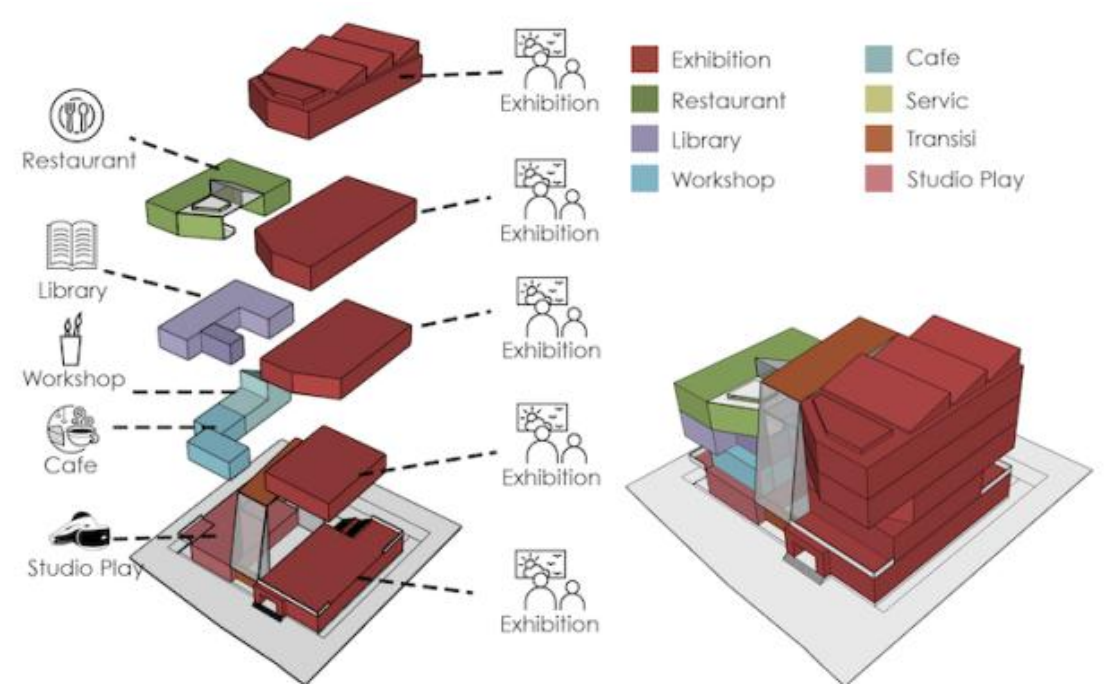

Gambar 11. Zoning

Sumber: Dokumen Pribadi, 2019

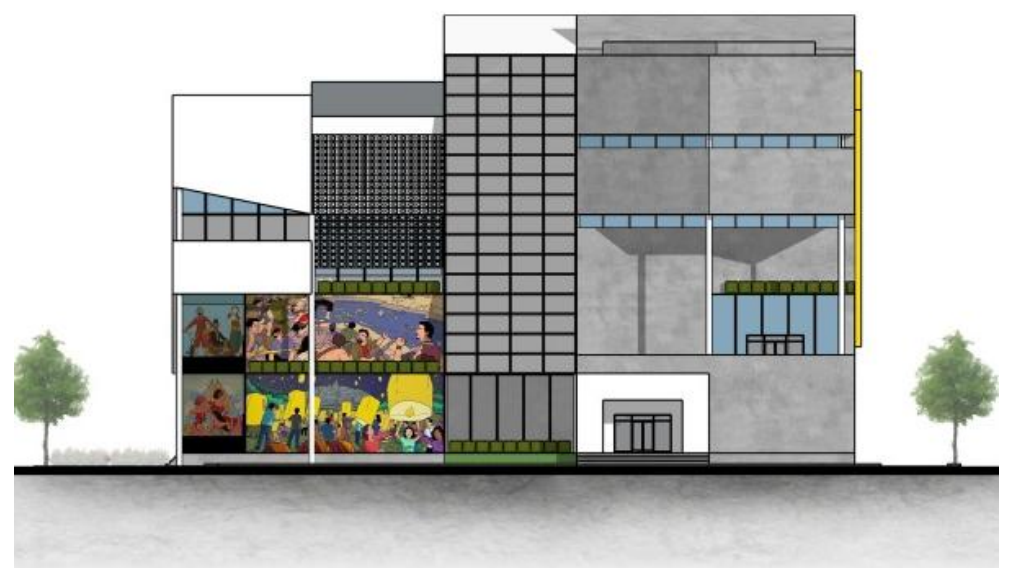

Gambar 12. Tampak Depan

Sumber: Dokumen Pribadi, 2019

Menggunakan seni mural pada bagian façade depan bangunan, sebagai apresiasi seni mural dalam seni rupa kontemporer. 


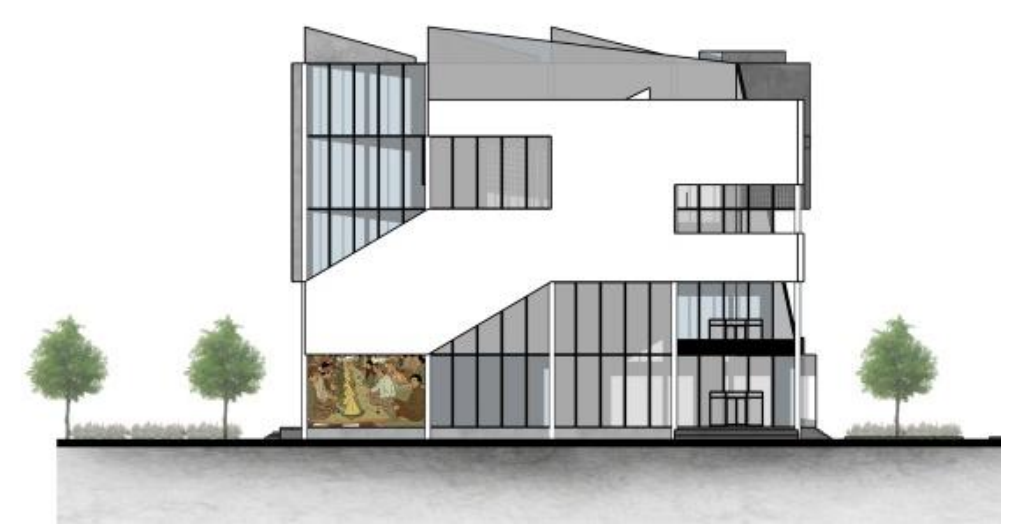

Gambar 13. Tampak Samping Kanan

Sumber: Dokumen Pribadi, 2019

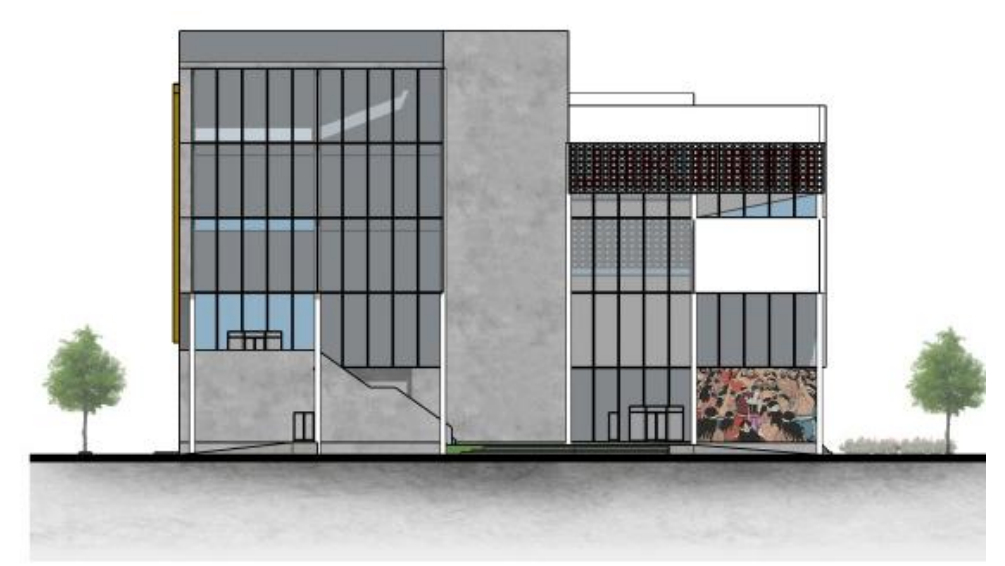

Gambar 14. Tampak Belakang

Sumber: Dokumen Pribadi, 2019

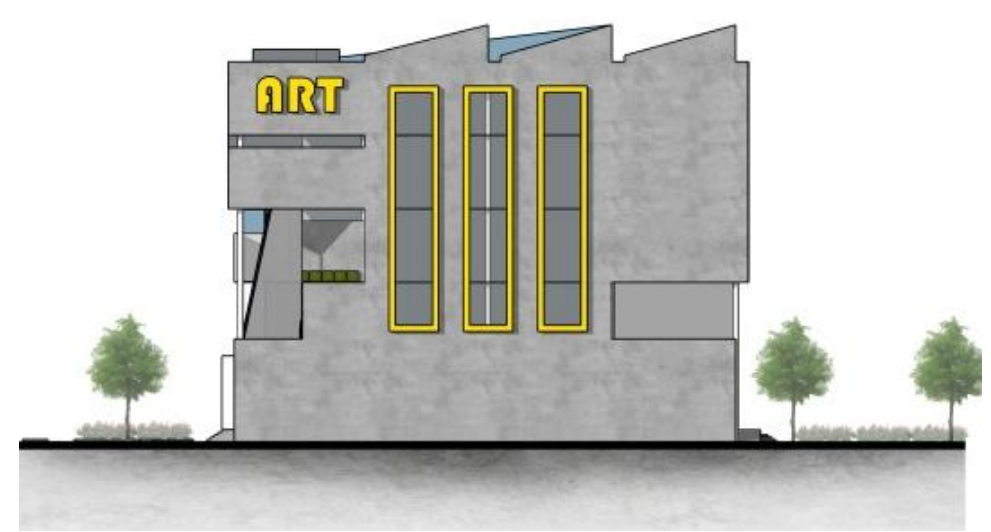

Gambar 15. Tampak Samping Kiri

Sumber: Dokumen Pribadi, 2019

Façade bangunan menggunakan beton dan alumunium composite panel (ACP) di berbagai sisi bangunan.

\section{Program dan Kegiatan}

Perhitungan kebutuhan ruang dari masing-masing program dimaksudkan untuk mendapatkan besaran luas tiap ruang melalui standard. Acuan yang digunakan untuk menentukan standard ruang dari masing-masing kegiatan, yaitu: Architect's Data, 1 \& 2, Ernst Neufert, John Wiley an Sons, New York, 1980 (Neufert,1980) 
Berikut nama ruang berdasarkan program yang terdapat di Galeri Seni Rupa Kontemporer adalah sebagai berikut:

Tabel 3. Program dan Kegiatan

\begin{tabular}{|c|c|}
\hline Kelompok Kegiatan & Kebutuhan Ruang \\
\hline \multicolumn{2}{|c|}{ Kegiatan Pengembangan } \\
\hline & $\begin{array}{l}\text { Area Parkir } \\
\text { Penitipan Barang } \\
\text { Front Desk } \\
\text { R. Pameran } \\
\text { Loker }\end{array}$ \\
\hline Kegiatan Pameran & $\begin{array}{l}\text { Area Parkir } \\
\text { Kantor Pengelola } \\
\text { Kantor Kuratorial } \\
\text { Loading Dock } \\
\text { R. Pameran } \\
\text { Loker } \\
\text { Musholla }\end{array}$ \\
\hline $\begin{array}{l}\text { Kegiatan Pertunjukan dan } \\
\text { Pemutaran Film }\end{array}$ & $\begin{array}{l}\text { Amphitheater Indoor } \\
\text { Amphitheater Terbuka } \\
\text { R. Persiapan } \\
\text { Gudang } \\
\text { Loker }\end{array}$ \\
\hline Kegiatan Studio Workshop & $\begin{array}{l}\text { Studio Workshop } \\
\text { R. Pameran } \\
\text { Gudang Alat } \\
\text { R.Studio Workshop } \\
\text { R.Pameran } \\
\text { Gudang Alat }\end{array}$ \\
\hline Kegiatan Diskusi Umum & $\begin{array}{l}\text { R. Persiapan } \\
\text { R. Serbaguna } \\
\text { Gudang }\end{array}$ \\
\hline \multicolumn{2}{|c|}{ Kegiatan Pendukung (Komersil) } \\
\hline Restaurant / Coffee Shop & $\begin{array}{l}\text { Bar } \\
\text { Area Duduk } \\
\text { Kasir } \\
\text { Loker } \\
\text { Gudang } \\
\text { Dapur Dan Bar } \\
\text { Area Duduk } \\
\end{array}$ \\
\hline VR (Virtual Reality) Zone & Area Mesin VR \\
\hline \multicolumn{2}{|l|}{ Kegiatan Penunjang } \\
\hline Studio Interaktif & $\begin{array}{l}\text { Layar Touchscreen } \\
\text { Monitor Proyeksi Kinect }\end{array}$ \\
\hline Perpustakaan & $\begin{array}{l}\text { Mencari Informasi } \\
\text { Berdiskusi }\end{array}$ \\
\hline
\end{tabular}

Sumber: Dokumen Pribadi, 2019 


\section{KESIMPULAN}

Galeri Seni Rupa Kontemporer di Cikini, Jakarta Pusat ini memiliki tujuan sebagai wadah apresiasi seni dan untuk memamerkan karya seni kontemporer kepada masyarakat sekaligus digunakan untuk memelihara karya seni tersebut. Selain itu terdapat Studio Interaktif yang berfungsi sebagai sarana memperkenalkan budaya dan seni dengan cara yang lebih modern yang dapat melibatkan pengunjung untuk lebih interaktif dengan media teknologi yang berkembang dan memberikan pengalaman yang berbeda.

Perancangan Galeri Seni Rupa Kontemporer ini mempunyai konsep memberikan pengalaman baru untuk menikmati sebuah karya seni dengan media yang berbeda-beda dan memberikan ruang publik yang dapat di pergunakan untuk berinteraksi dan bersantai.

\section{UCAPAN TERIMA KASIH}

Puji dan syukur saya ucapkan kepada Tuhan yang Maha Esa karena berkat rahmat dan karunia Allah SWT, penulis dapat menyelesaikan jurnal ini yang berjudul Galeri Seni Rupa Kontemporer. Penulis juga mengucapkan terima kasih kepada pihak-pihak lainnya yang telah memberikan pengarahan, petunjuk dan bimbingan yang memungkinkan terselesaikannya penulisan ini. Penulis menyadari masih banyak kekurangan dalam penulisan ini, namun penulis berharap semoga laporan ini bermanfaat bagi yang membacanya.

\section{REFERENSI}

Neufert, John Wiley and Sons. (1980). Architect's Data, 1 \& 2. New York. Specht, Jan. (2014). Architectural Tourism Building for Urban Travel Destination.

Statistik Informasi Pariwisata DKI Jakarta, diunduh 11 Agustus 2018, www.jakarta.bps.go.id. 